Fixed Point Theory, 20(2019), No. 1, 233-244

DOI: $10.24193 /$ fpt-ro.2019.1.15

http://www.math.ubbcluj.ro/ nodeacj/sfptcj.html

\title{
A NONLOCAL PROBLEM FOR PROJECTED DIFFERENTIAL EQUATIONS AND INCLUSIONS WITH APPLICATIONS
}

\author{
NGUYEN VAN LOI*A,B, MAI QUOC VU**, NGUYEN THI HOAI*** AND VALERI \\ OBUKHOVSKII**** \\ ${ }^{* a}$ Division of Computational Mathematics and Engineering \\ Institute for Computational Science \\ Ton Duc Thang University, Ho Chi Minh city, Viet Nam \\ ${ }^{b}$ Faculty of Civil Engineering \\ Ton Duc Thang University, Ho Chi Minh city, Viet Nam \\ E-mail: nguyenvanloi1@tdtu.edu.vn \\ ${ }^{* *}$ Faculty of Natural Sciences and Technology \\ Tay Nguyen University, Viet Nam \\ E-mail: maiquocvu@gmail.com \\ *** Department of Mathematics, Mechanics and Informatics \\ VNU, University of Science, Hanoi, Viet Nam \\ E-mail: nthoai0682@yahoo.com \\ **** Department of Physics and Mathematics \\ Voronezh State Pedagogical University, Voronezh, Russia \\ E-mail: valerio-ob2000@mail.ru
}

\begin{abstract}
We study a nonlocal problem for projected differential equations and inclusions in finite dimensional spaces. By applying the fixed point theory methods we obtain the existence of solutions to the considered problem for projected differential inclusions. For the case of the projected differential equations we prove, under some suitable conditions, the uniqueness of a solution and the Ulam-Hyers stability of solutions. It is shown how the abstract results can be applied to the study of a market model with the price intervention in the form of price floors and ceilings. An example with exponential demand and supply functions is presented.

Key Words and Phrases: Projected differential inclusion, nonlocal condition, fixed point, UlamHyers stability, market model.
\end{abstract}

2010 Mathematics Subject Classification: 34B15, 47H10, 34A60, 34D20, 91B26.

Acknowledgements. The authors are obliged to the referee for his/her valuable remarks. The work of V. Obukhovskii is supported by the Ministry of Education and Science of the Russian Federation (Project No 1.3464.2017/4.6) and by the RFBR grants 17-51-52022, 16-01-00370, and 16-01-00386. 


\section{REFERENCES}

[1] A.V. Arutyunov, V. Obukhovskii, Convex and Set-Valued Analysis. Selected Topics, Walter de Gruyter, Berlin-Boston, 2016.

[2] R. Bader, W. Kryszewski, Fixed-point index for compositions of set-valued maps with proximally $\infty$-connected values on arbitrary ANR's, Set-Valued Anal., 2(1994), no. 3, 459-480.

[3] V. Barbu, Nonlinear Semigroups and Differential Equations in Banach Spaces, Noordhoff International Publishing, Leyden, 1976.

[4] Y.G. Borisovich, B.D. Gelman, A.D. Myshkis, V.V. Obukhovskii, Introduction to the Theory of Multivalued Maps and Differential Inclusions, (Russian), Second edition, Librokom, Moscow, 2011.

[5] K. Borsuk, Theory of Retracts, Monografie Mat., 44, PWN, Warszawa, 1967.

[6] L. Byszewski, Theorems about the existence and uniqueness of solutions of a semilinear evelotion nonlocal Cauchy problem, J. Math. Anal. Appl., 162(1991), 494-505.

[7] M.-G. Cojocaru, Monotonicity and existence of periodic orbits for projected dynamical systems on Hilbert spaces, Proc. Amer. Math. Soc., 134(3)(2006), 793-804.

[8] M.-G. Cojocaru, L.B. Jonker, Existence of solutions to projected differential equations in Hilbert spaces, Proc. Amer. Math. Soc., 132(1)(2004), 183-193.

[9] B. Cornet, Existence of slow solutions for a class of differential inclusions, J. Math. Anal. Appl., 96(1983), 130-147.

[10] S.S. Dragomir, Some Gronwall Type Inequalities and Applications, Nova Science Publishers, Inc., New York, 2003.

[11] L. Górniewicz, Topological Fixed Point Theory of Multivalued Mappings, Second Edition, Springer, Dordrecht, 2006.

[12] C. Henry, An existence theorem for a class of differential equations with multivalued right-hand side, J. Math. Anal. Appl., 41(1973), 179-186.

[13] D.H. Hyers, G. Isac, Th.M. Rassias, Topic in Nonlinear Analysis and Applications, World Scientific, Singapore, New Jersey, London, Hong Kong, 1997.

[14] D.M. Hyman, On decreasing sequences of compact absolute retracts, Fund Math., 64(1969), 91-97.

[15] M. Kamenskii, V. Obukhovskii, P. Zecca, Condensing Multivalued Maps and Semilinear Differential Inclusions in Banach Spaces, Walter de Gruyter, Berlin-New York 2001.

[16] A.D. Myshkis, Generalizations of the theorem on a fixed point of a dynamical system inside of a closed trajectory, (Russian), Mat. Sb., 34(3)(1954), 525-540.

[17] A. Nagurney, Network Economics: A Variational Inequality Approach, Second and Revised Edition, Kluwer Academic Publisher, Dordrecht, 1999.

[18] A. Nagurney, D. Zhang, Projected dynamical systems and variational inequalities with applications, Kluwer Academic Publishers, Boston, Massachusetts, Amherst, Massachusetts, 1996.

[19] A. Nagurney, D. Zhang, On the stability of an adjustment process for spatial price equilibrium modeled as a projected dynamical system, J. Econom. Dynam. Control, 20(1-3)(1996), 43-62.

[20] V. Obukhovskii, P. Zecca, N.V. Loi, S. Kornev, Method of Guiding Functions in Problems of Nonlinear Analysis, Lecture Notes in Math. 2076, Springer-Velag, Berlin-Heidelberg, 2013.

[21] D. Zhang, A. Nagurney, On the stability of projected dynamical systems, J. Optim. Th. Appl., 85(1)(1995), 97-124.

Received: October 12, 2017; Accepted: March 16, 2018. 